Www.jmscr.igmpublication.org

Index Copernicus Value: 79.54

ISSN (e)-2347-176x ISSN (p) 2455-0450

crossref DOI: https://dx.doi.org/10.18535/jmscr/v7i6.124

Journal Of Medical Science And Clinical Research

IGM Publication

An official Publication of IGM Publication

\title{
Comparison of Suxamethonium and Rocuronium on time to Oxygen Desaturation during Apnoea Following Rapid Sequence Induction- A Randomized Controlled Trial
}

\author{
Authors
}

Dr Malyashree Roy M.D ${ }^{1}$, Dr Neetika Mishra M.D ${ }^{2^{*}}$, Dr Ahito Kibami M.B.B.S ${ }^{3}$

${ }^{1}$ RMO cum clinical tutor, Calcutta National Medical College, Kolkata, West Bengal

${ }^{2}$ Associate Professor, Dept. of Anaesthesiology, North Bengal Medical College, Darjeeling, West Bengal

${ }^{3}$ Post Graduate trainee, Dept. of Anaesthesiology, North Bengal Medical College, Darjeeling, West Bengal

*Corresponding Author

Dr Neetika Mishra M.D

Associate Professor, Dept. of Anaesthesiology, North Bengal Medical College, Darjeeling, West Bengal

Abstract
Hypoxia and hypoxic related injuries remain the main cause of anaesthesia related death and serious
morbidity. The study has been focused on maximising the intrapulmonary oxygen reserve to prolong non-
hypoxic apnoea duration. Various technique of preoxygenation including rebreathing with high fresh gas
flow, application of positive airway pressure during preoxygenation, nasopharyngeal oxygen insufflation
following preoxygenation can delay the onset of arterial desaturation during apnoea. The present study was
carried out with the primary objective of comparing between suxamethonium and rocuronium as agent for
rapid sequence induction with respect to the time required for oxygen saturation to decrease to $92 \%$ in
seconds following apnoea. It was hypothesized that suxamethonium would be associated with shorter time
to desaturate from administration until oxygen saturation was $92 \%$.
In the present studies 66 patients were divided into two groups: Group $S$ (n=33) for suxamethonium and
Group $R$ ( $n=33$ ) for rocuronium and their datas was analysed.
Significant difference was detected in the time taken for oxygen saturation to decreased to $92 \%$ between the
two group (p=0.042). Haemodynamic parameters both at intubation and post-intubation at 2 minutes were
comparable and showed no significant differences.
Keywords: safe apnea, suxamethonium, rocuronium, rapid sequence intubation.

\section{Introduction}

Patients scheduled for elective surgeries are usually in optimal physical and mental condition with a definitive surgical diagnosis. In contrast, the patient with the surgical emergency may have an uncertain diagnosis and uncontrolled coexisting disease.

Vomiting or regurgitation of gastric contents followed by aspiration while the protective laryngeal reflexes are obtunded is one of the commonest and devastating hazards of emergency anaesthesia. The presence of vomitus above the vocal cord causes spasm in lighter plane resulting in apnoea which may persist and results to severe hypoxemia or even cardiac arrest. Even if the spasm does resolves, aspiration may occur unless a supraglottic debris has been cleared before resumption of ventilation. 
Rapid-sequence induction (RSI) is the technique most frequently used for a patient with full stomach as it minimizes the duration of time between loss of consciousness and tracheal intubation during which the patient is at greater risk of aspiration.

The traditional technique of RSI as described in the original publication ${ }^{1}$ entails administration of a precalculated dose of induction agents followed immediately by a neuromuscular blocking agent after adequate preoxygenation. Cricoid pressure at 20-40 $\mathrm{N}$ is applied before loss of consciousness. After the jaw relaxes and succinylcholine associated fasciculation ceased, the trachea is intubated and cuff inflated. Positive pressure ventilation is avoided before tracheal intubation ${ }^{1,2}$. After the tube positioninga and adequate seal are confirmed cricoid pressure is released. However, differences have been noted in the perception and execution of RSI among amaesthesiologist ${ }^{3}$ and might reflect the current controversy regarding some of the technique in traditional components. This may be the reason for failure to establish a standard RSI protocol.

Traditionally, succinylcholine which is also known as suxamethonium has been the neuromuscular blocking drugs (NMBD) of choice for RSI because of its two desirable properties: a rapid onset of action which facilitates speedy intubation, thereby minimizes the risk of aspiration, while a short duration of action allows for quicker onset of spontaneous respiration in the event of failed intubation.

However, it causes a number of adverse effects which includes increased serum potassium concentration, myalgia, and rarely malignant hyperthermia. Myalgia caused by suxamethonium is due to fasciculations which increases the wholebody oxygen consumptions. ${ }^{4,5}$ Increased oxygen consumption is one of the factors that may have a major effect on time to oxygen desaturation following apnoea during induction of anaesthesia ${ }^{6}$. High dose of rocuronium $(0.9-1.2 \mathrm{mg} / \mathrm{kg}$ ) has been suggested as an alternative for RSI as it achievesa intubating condition in a comparative time as suxamethonium ${ }^{7,8,26}$ but its use has been limited by a more prolonged duration of action. However, the availability of the sugammadex enables high dose rocuronium to be used a $\mathrm{s}$ an alternative to suxamethoniumin RSI. Sugammadex allows a rapid reversal through encapsulation of the rocuronium molecule. Studies have shown that non-depolarizing NMBD do not alter oxygen consumption in anaesthetized patient ${ }^{4,5,6,9}$ since the muscular tone is already reduced by GA.

Apnoea is always present during RSI in GA. Maintaining haemoglobin saturation during airway management is critical for patient's safety. Desaturation to below $70 \%$ puts patient at risk of dysrhythmia, hemodynamic decompensation, hypoxic brain injury and death ${ }^{10,11}$. It is potentially life threatening if it is inadequately managed.

This study was planned to give an idea about the rapidity with which desaturation occurs with the two NMBD- suxamethonium and rocuronium. It was designed to compare the time taken by both the drug to desaturate till $92 \%$ during apnoea following RSI and was hypothesized that suxamethonium would be associated with a shorter time to desaturate.

\section{Materials and Methods}

The prospective randomized control double-blind study was conducted after getting approval from the hospital ethic committee. Patient within the age of 23-60 years; height within the range of 140-165 cm; weight between $50-70 \mathrm{~kg}$ and belonging to ASA physical status grade I and II scheduled for elective surgery were included in the study. Exclusion criteria included patient not willing to participate in the study, pregnant patients, history of significant pulmonary pathology or significant cardiovascular disease, person with $\mathrm{BMI}>26 \mathrm{~kg} / \mathrm{m}^{2}$, anticipated difficult intubation, patients having a history of malignant hyperthermia, recent burnt, abdominal sepsis and prolonged immobilization.

If any difficulty was encountered during induction or intubation, appropriate action was taken by the 
anaesthesiologist to optimize the patient and the patient was excluded from the study.

The number of patients in each group was calculated to be 30 , by considering type 1 error $\alpha=0.005$ and the power of the study $(1-\beta)$ to be $80 \%$, where type 2 error $(\beta=0.20)$. A 30 second difference was considered clinically relevant ${ }^{12}$ and standard deviation was taken to be 34 seconds from a pilot study conducted earlier. Considering a drop-out rate of $20 \%$ a sample size of 72 patients was considered. A P value $<0.05$ was considered significant. A sample size of 72 patients was initially taken considering the inclusion and exclusion criteria. Out of them, 4 patients opted out of the studies, finally 68 patients were randomized into two groups of 34 each to receive either $\mathrm{SCH} 1 \mathrm{mg} / \mathrm{kg}$ (group $\mathrm{S}$ ) or injection Rocuronium 1mg/kg (group R). Two patients developed complications after induction and had to be excluded from the studies so data from 62 patients was available for analysis; group $S(n=33)$ and group $\mathrm{R}(\mathrm{n}=33)$.

After admission of the patients, a repeat preanesthetic check up was done where they were explained about the procedure in their own vernacular language and written informed consent was taken. The patients were advised oral Ranitidine $150 \mathrm{mg}$ the night before the surgery, on the day of surgery, $18 \mathrm{G}$ IV cannula was established and infusion commenced. After shifting the patient to the operating room, they were allocated two different room by lottery method subsequently the monitor (NIBP, SPO2) were attached. Baseline haemodynamic variables (HR, MAP) were recorded. All patients received premedication with $0.02 \mathrm{mg} / \mathrm{kg}$ midazolam IV before induction. Anaesthesia was administered by an experienced anaesthesiologist. To minimise bias an independent investigator was assigned to record the data who was called after the administration of the NMBD. Thus, both the patient and the investigator were blinded to the study.

Patient were preoxygenated with $100 \%$ oxygen in the supine position using a tight fitting non- rebreathing facemask $^{13}$ with the bag for 3 minutes $^{14,15}$ and the patient was asked to breath normally. Anaesthesia was then induced using the RSI technique.

For induction, injection propofol $(2 \mathrm{mg} / \mathrm{kg})$ was administered over 20 seconds accompanied by injection fentanyl $(2 \mathrm{mcg} / \mathrm{kg})$. Either injection $\mathrm{SCH}$ $(1 \mathrm{mg} / \mathrm{kg})$ or rocuronium $(1 \mathrm{mg} / \mathrm{kg})$ were given upon loss of verbal contact. The facemask was removed 60secs after the administration of $\mathrm{NMBD}^{16,17}$ and was followed by laryngoscopy and tracheal intubation. Stop watch was started from the time the facemask was removed ${ }^{12}$. The tracheal tube was left open to air until oxygen saturation decline to $92 \%$, at this point the stopwatch was stopped. Oxygen saturation was continuously monitored, once it declined to $92 \%$, the patient was connected to the ventilator. Anaesthesia was maintained with the muscle relaxant as required. The time from onset of apnoea to the time that oxygen saturation reached 92\% was compared among the two group. The mean arterial pressure and heart rate at intubation and 2 mins post-intubation was also recorded and compared.

\section{Result and Analysis}

A sample size of 72 patients was initially taken considering the inclusion and exclusion criteria. Out of them, 4 patients opted out of the studies, finally 68 patients were randomized into two groups of 34 each to receive either $\mathrm{SCH} 1 \mathrm{mg} / \mathrm{kg}$ (group S) or injection Rocuronium $1 \mathrm{mg} / \mathrm{kg}$ (group R). Two patients developed complications after induction and had to be excluded from the studies so data from 66 patients was available for analysis; group $\mathrm{S}(\mathrm{n}=33)$ and group $\mathrm{R}(\mathrm{n}=33)$.

Observations were tabulated in an excel sheets and analysed. Continuous data were expressed as mean \pm SD. Discrete categorical data were presented as number of patients $[\mathrm{n}(\%)]$. comparison of continuous data with a normal distribution were performed using the independent student's t test. Categorical data were analysed with contingency tables using Pearson Chi-square 
test. Statistical test was considered significant when $\mathrm{p}$ value $<0.005$. All analysis was conducted using SPSS for window (version 19.0; SPSS Inc., Chicago, IL)

Table 1 Demographic variables of the patients

\begin{tabular}{|c|c|c|c|c|}
\hline Parameter & & Group $S(n=33)$ & Group R (n=33) & P value \\
\hline \multirow[b]{2}{*}{ Age (years) } & Mean & 23.96 & 23.84 & \multirow[t]{2}{*}{$0.871(\mathrm{NS})$} \\
\hline & $\mathrm{SD}$ & \pm 2.82 & \pm 3.23 & \\
\hline \multirow[b]{2}{*}{ Weight (kg) } & Mean & 61.45 & 61.36 & \multirow[t]{2}{*}{$0.903(\mathrm{NS})$} \\
\hline & SD & \pm 2.03 & \pm 3.78 & \\
\hline \multirow[b]{2}{*}{ Height(cm) } & Mean & 153.87 & 153.78 & \multirow[t]{2}{*}{$0.915(\mathrm{NS})$} \\
\hline & $\mathrm{SD}$ & \pm 3.29 & \pm 3.62 & \\
\hline \multirow[b]{2}{*}{ BMI $\left(\mathrm{kg} / \mathrm{m}^{2}\right)$} & Mean & 26.0 & 25.97 & \multirow[t]{2}{*}{$0.961(\mathrm{NS})$} \\
\hline & $\mathrm{SD}$ & \pm 1.63 & \pm 1.91 & \\
\hline \multirow[b]{2}{*}{ ASA status } & $\mathrm{I}$ & 20 & 18 & \multirow[t]{2}{*}{$0.969(\mathrm{NS})$} \\
\hline & II & 13 & 15 & \\
\hline \multirow[b]{2}{*}{ M:F } & $\mathrm{M}$ & 17 & 16 & \multirow[t]{2}{*}{$0.996(\mathrm{NS})$} \\
\hline & $\mathrm{F}$ & 16 & 17 & \\
\hline
\end{tabular}

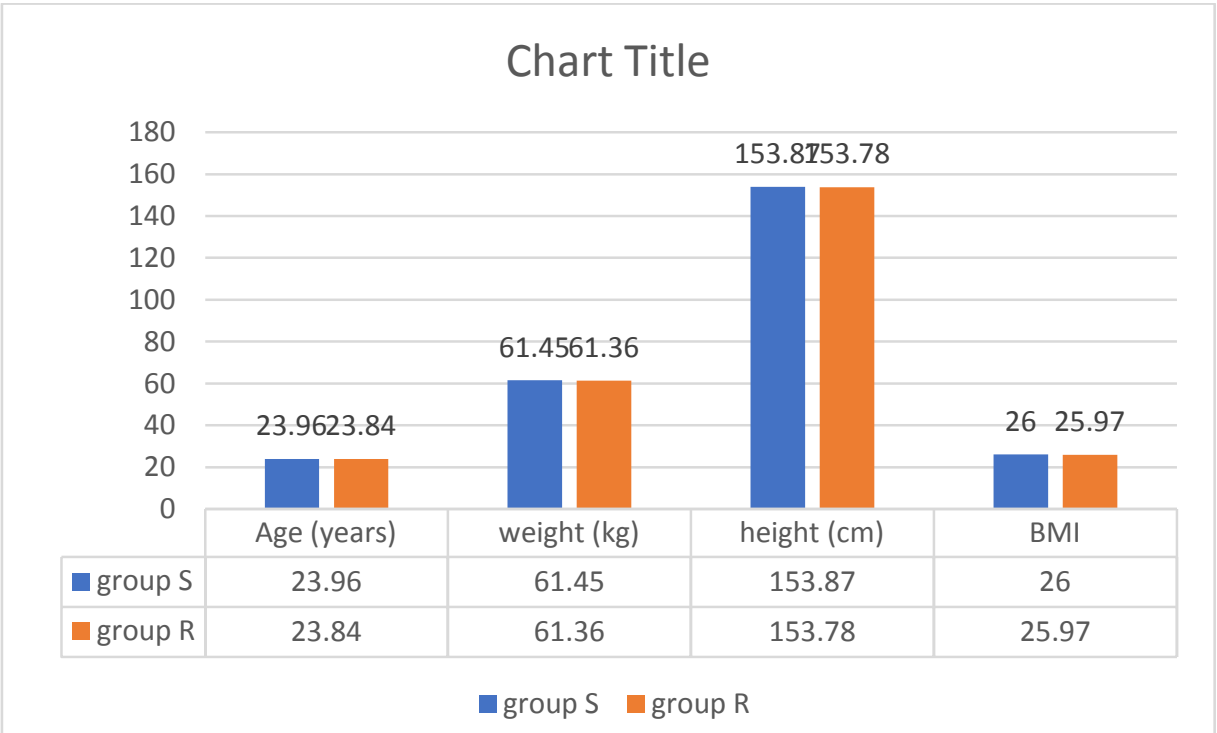

Bar diagram showing distribution of patients according to age(years), weight(kg), height(cm), BMI in Group S and Group R.

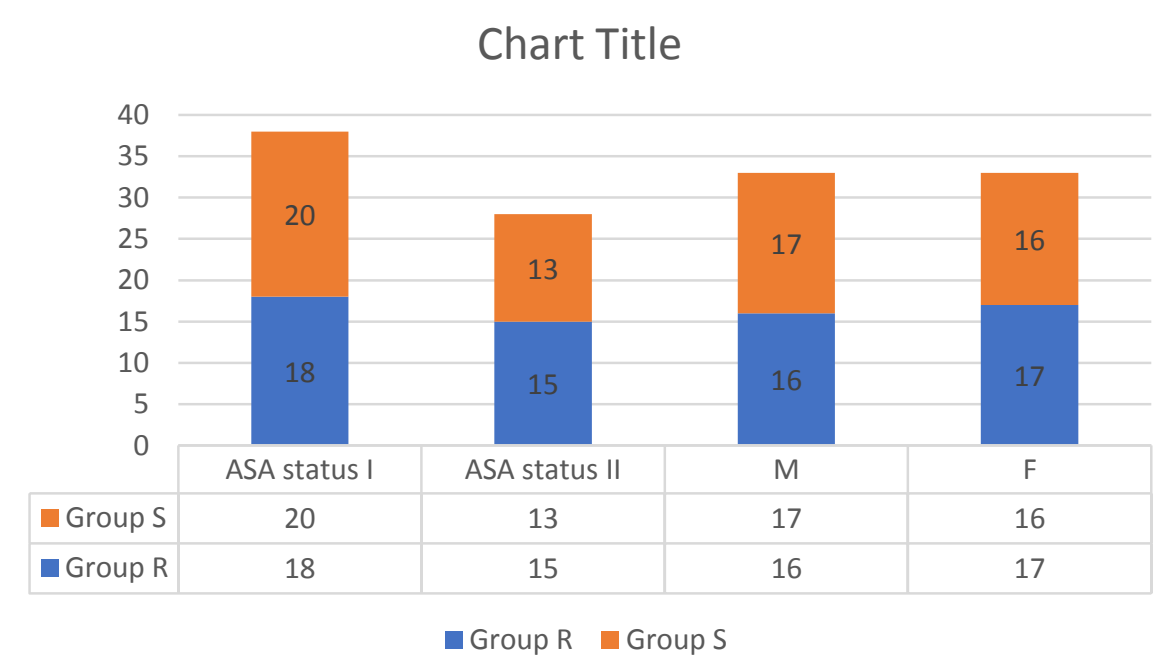

Bar diagram showing distribution of patients according to sex (male: female) and ASA status (I and II) 
Table 2 Distribution of patients according to $\mathrm{Hb}(\mathrm{gm} / \mathrm{dL})$, baseline MAP (mm of $\mathrm{Hg}$ ), baseline heart rate (beats per minute)

\begin{tabular}{|c|c|c|c|c|}
\hline Parameter & & $\begin{array}{c}\text { Group } S \\
(n=33)\end{array}$ & $\begin{array}{c}\text { Group R } \\
(n=33)\end{array}$ & $P$ value \\
\hline \multirow[b]{2}{*}{$\mathrm{Hg}(\mathrm{gm} / \mathrm{dL})$} & Mean & 12.85 & 12.45 & \multirow[b]{2}{*}{$0.067(\mathrm{NS})$} \\
\hline & $\mathrm{SD}$ & \pm 0.78 & \pm 0.93 & \\
\hline \multirow{2}{*}{$\begin{array}{l}\text { Baseline } \\
(\mathrm{mmHg})\end{array}$} & Mean & 90.27 & 91 & \multirow[b]{2}{*}{$0.357(\mathrm{NS})$} \\
\hline & $\mathrm{SD}$ & \pm 3.06 & \pm 3.30 & \\
\hline \multirow{2}{*}{$\begin{array}{l}\text { Baseline heart rate } \\
\text { (bmp) }\end{array}$} & Mean & 85.42 & 84 & \multirow[b]{2}{*}{$0.299(\mathrm{NS})$} \\
\hline & SD & \pm 5.45 & \pm 5.60 & \\
\hline
\end{tabular}

Table 3 Comparison of $\mathrm{SO}_{2}(\%)$ for group $\mathrm{S}$ and group $\mathrm{R}$ and their statistical analysis

\begin{tabular}{|c|c|c|c|}
\hline & $\begin{array}{l}\text { Group } \\
(n=33)\end{array}$ & $\begin{array}{l}\text { Group } \\
(\mathrm{n}=33)\end{array}$ & $P$ value \\
\hline Mean & 97.57 & 97.48 & \\
\hline SD & \pm 1.22 & \pm 1.09 & $0.751(\mathrm{NS})$ \\
\hline
\end{tabular}

Table 4 Comparison of mean arterial pressure (MAP) at intubation and 2 mins post intubation for group $\mathrm{S}$ and group $\mathrm{R}$ and their statistical analysis

\begin{tabular}{|l|c|c|c|l|}
\hline Parameter & & Group S (n=33) & Group R (N=33) & P value \\
\hline \multirow{3}{*}{ MAP at intubation (mmHg) } & Mean & $\mathbf{8 2 . 0 9}$ & $\mathbf{8 2 . 1 5}$ & \\
\cline { 2 - 5 } & SD & \pm 2.97 & \pm 2.99 & \multirow{2}{*}{$0.934(\mathbf{N S})$} \\
\hline \multirow{3}{*}{ MAP at 2 mins (mmHg) } & Mean & $\mathbf{7 7 . 8 7}$ & $\mathbf{7 8 . 2 7}$ & \multirow{2}{*}{$0.630(\mathrm{NS})$} \\
\cline { 2 - 5 } & SD & \pm 3.21 & \pm 3.39 & \\
\end{tabular}

Table 5 Comparison of Heart rate at intubation and 2 minutes post intubation for group $\mathrm{S}$ and group $\mathrm{R}$ and their statistical analysis

\begin{tabular}{|l|c|c|c|c|}
\hline Parameter & & Group S $(\mathrm{n}=33)$ & Group R $(\mathrm{N}=33)$ & P value \\
\hline \multirow{3}{*}{ HR at intubation (mmHg) } & Mean & $\mathbf{9 0 . 2 1}$ & $\mathbf{9 0 . 6 0}$ & \\
\cline { 2 - 5 } & SD & \pm 5.39 & \pm 5.44 & $0.768(\mathrm{NS})$ \\
\hline \multirow{3}{*}{ HR at 2 mins (mmHg) } & Mean & $\mathbf{8 8 . 1 2}$ & $\mathbf{8 8 . 3 3}$ & \multirow{2}{*}{$0.863(\mathrm{NS})$} \\
\cline { 2 - 4 } & SD & \pm 4.92 & \pm 5.08 & \\
\hline
\end{tabular}

Table 6-Comparison of time for oxygen saturation to reach 92\% (in seconds) for group S and Group R with their statistical analysis

\begin{tabular}{|l|c|c|c|}
\hline & Group S $(\mathbf{n}=33)$ & Group $\mathbf{R}(\mathbf{n}=33)$ & P value \\
\hline Mean & 292.24 & 315.78 & \multirow{2}{*}{ O.042(S) } \\
\cline { 1 - 3 } SD & \pm 63.77 & \pm 4.59 & \\
\hline
\end{tabular}

\section{Discussion}

Anaesthesia for emergency surgery can be termed unplanned as the patients are not evaluated preoperatively for the surgery. Most of these patients who need emergency surgery have compromised vital function and hence are at greater risk of developing life-threatening complications like hypoxia, dysrhythmia, shock, cardiac arrest and even death. Careful selection of anaesthesia technique, drugs and dosage depending on the patient's clinical conditions are thus vital components for the safe conduct of anaesthesia. Full stomach should be assumed in such patient. RSI is an anaesthesia technique designed to facilitated rapid tracheal intubation at high risk of aspiration. The main objective of the technique is to minimize the time interval between the loss of protective airway reflexes and tracheal intubation since the airway is unprotected during this time, it is the most critical period during which aspiration of gastric content is likely to occur1. Hypoxia usually occurs during apnoea in 
RSI, and is more pronounced in patients with uncontrolled coexisting diseases.

Hypoxia and its related injuries remain the main cause of anaesthesia related death and serious morbidity. Current studies have been focused on maximising the intra-pulmonary oxygen reserve to prolong non-hypoxic apnoea duration. Various technique of "pre-oxygenation", including deep breathing with high fresh gas flow of oxygen ${ }^{18}$, application of positive airway pressure during preoxygenation $^{19,20}$ and nasopharyngeal oxygenation following preoxygenation ${ }^{21,22}$ which can delay the onset of arterial oxygen desaturation during apnoea have been developed. The head up position has been recommended to optimise preoxygenation $^{23-26}$.

Succinylcholine is the most commonly used depolarizing NMBD in RSI because of its fast onset and short duration. Unfortunately, it increases muscle oxygen consumption as a result of skeletal muscle fasciculation ${ }^{27}$ and it cause serious side-effect such as malignant hyperthermia in some sensitive cases. Rocuronium, an intermediate acting non-depolarizing muscle relaxant, has an onset of action that is more rapid than others. It is well-documented alternative to succinylcholine for intubation in $\mathrm{RSI}^{7,8}$. With the introduction of sugammadex, its action can be reversed within 3 minutes. Though succinylcholine provides better intubating conditions in minimum time ${ }^{28,29}$, it causes more rapid desaturation as documented in previous studies $^{12}$. Hypoxia resulting from this rapid desaturation becomes detrimental more so in the patients posted for emergency surgeries. Non hypoxic apnoea duration also known as period of safe apnoea is the time till the oxygen saturation reaches $88-90 \%$. When patients desaturate below this level, their status in on the steep portion of the oxy-haemoglobin dissociation curve and can decrease to critical levels $(70 \%)$ within seconds ${ }^{30}$. The present study investigated the non-hypoxic apnoea duration during induction of general anaesthesia using RSI technique.
In our study 66 patients were randomly allocated into 2 groups of 33 each to receive either injection suxamethonium (group $S$ ) or injection Rocuronium (group R) following induction with propofol and fentanyl. Sixty seconds after administration of neuromuscular blocking drug, face mask was removed and the patient was intubated. The tracheal tube was left open to air till saturation reached $92 \%$. Time to desaturate was calculated from the time when the face mask was removed. The 2 groups were comparable with respect to age, sex, weight, height, $\mathrm{BMI}, \mathrm{Hb} \%$, ASA status and baseline oxygen saturation.

The main finding of the study was that safe apnoea time was significantly shorter for suxamethonium 292.24 \pm 63.77 seconds compared to rocuronium $315.78 \pm 4.59$ seconds ( $\mathrm{p}=0.042$ ). The rapid desaturation caused by suxamethonium may be attributed to the increased muscle oxygen consumption due to fasciculations. The result of our study corroborated with the results obtained from studies conducted by Taha et $\mathrm{al}^{31}(2010)$ and Tang et.al ${ }^{12}$ (2011).

There was no statistically significant difference between the HR immediately after intubation between group $\mathrm{S} 90.21 \pm 5.39$ beats/min and group R $90.60 \pm 5.44$ beats/min $(p+0.768)$. there was no significance between group $\mathrm{S}$ 88.12 \pm 4.92 beats/min and group R $88.33 \pm 5.08$ beats/minwith respect to heart rate 2 mins post intubation.

No significance difference $(p=0.934)$ was noted between the MAP immediately after intubation which was $82.09 \pm 2.97 \mathrm{~mm} \mathrm{Hg}$ for group $\mathrm{S}$ and $82.15 \pm 2.99 \mathrm{~mm} \mathrm{Hg}$ for group R, MAP at 2 mins post intubation $77.87 \pm 3.21 \mathrm{~mm} \mathrm{Hg}$ for group $\mathrm{S}$ and 78.27 \pm 3.39 for group $\mathrm{R}$ which was statistically non-significant $(\mathrm{p}=0.630)$. Our results corroborated with the findings of the study conducted in 2010 by Taha et $\mathrm{al}^{31}$.

In the present study, no intubation surge in respect to HR and MAP was noted in respect to both the groups. The supplementation of fentanyl as an agent may have resulted in the stable hemodynamic in both groups. Similar study was conducted in a study by Harris CE et $\mathrm{al}^{32}$, who 
found that administration of fentanyl $2 \mathrm{mcg} / \mathrm{kg}$ before thiopental, propofol or etomidate plus succinylcholine resulted in more stable hemodynamic profile than seen without the use of fentanyl.

According to previous studies, we constructed a desaturation model and ensured that the procedure were under control and $\mathrm{safe}^{31,25}$, for our study we considered the safe apnoea time from the administration of the NMBD to the time when oxygen desaturation declined to $92 \%$. It was considered as a safe end point in normal patient not at risk of developing hypoxemia because at that saturation arterial oxygen tension was acceptable and there was no significant Carbon dioxide accumulation ${ }^{12}$.

In the present study, we used injection Propofol as the induction agent. In the original description of rapid sequence induction, Stept and Safar ${ }^{1}$ used thiopental in 80 patients with satisfactory results. However, rapid administration of thiopental can result in serious hemodynamic side effects ${ }^{33}$. Dobson et al. ${ }^{34}$ compared propofol and thiopental for RSI with rocuronium $0.6 \mathrm{mg} / \mathrm{kg}$ and found better intubating conditions in the propofol group. Barr and Thornley ${ }^{35}$ compared the total time to intubation when thiopental and succinylcholine were given either in rapid succession or by titration to loss of consciousness and found that the titration group had a shorter mean time to intubation (70vs78 seconds). In our study we used sleep dose technique and titrated the induction agent till loss of consciousness was achieved.

We co-administered inj. Fentanyl $2 \mu \mathrm{g} / \mathrm{kg}$ with inj. propofol during induction. Administration of fentanyl $2 \mu \mathrm{g} / \mathrm{kg}$ before thiopental, propofol or etomidate plus succinylcholine resulted in more stable hemodynamic than seen without the use of fentanyl ${ }^{32}$.

\section{Conclusion}

In the emergency department, most of the patients are in a decompensated state. The effect of shunting, increased metabolic demand, anaemia, volume depletion and decreased cardiac output are synergistic in reducing the functional capacity and thereby shortening the period of safe apnoea in critically ill patient. In these cases, the neuromuscular blocking drug which causes more desaturation becomes important. From our study it was concluded that succinylcholine related muscle fasciculations has been cited as the most probable reason for this finding. Hence, in patients at high risk of desaturation rocuronium may provide a longer duration of safe apnoea and so may be a better choice as NMBD over succinylcholine.

\section{References}

1. Stept WJ, Safar P. Rapid induction/ intubation for prevention of gastric-content aspiration. AnesthAnalg 1970; 49: 633-36.

2. Suresh MS, Munnur U, Wali A. The patient with a full stomach. In: Hagberg CA, ed. Benumof's Airway Management: Principles and Practice. 2nd ed. Philadelphia, PA: Mosby, 2007:764 - 6.

3. Koerber JP, Roberts GEW, Whitaker R, Thorpe CM. Variation in rapid sequence induction techniques: current practice in Wales. Anaesthesia 2009; 64: 54-9.

4. Muldoon SM, Theye RA. The effects of succinylcholine and dtubocurarine on oxygen consumption. Anesthesiology 1969; 31: 437-42.

5. Theye RA, Brown AL, Van Dyke RA. The effects of halothane and succinylcholine on oxygen uptake of the canine gracilis muscle. Anesthesiology 1971; 35: 304-8

6. Hardman, J.G., J.S. Wills, and A.R. Aitkenhead, Factors determining the onset and course of hypoxemia during apnea: an investigation using physiological modelling. Anesthesia\& Analgesia, 2000; 90: 619-24.

7. McCourt KC, Salmela L, Mirakhur RK, Carroll M, Makinen MT, Kansanaho M, Kerr C, Roest GJ, Olkkola KT: Comparison of rocuronium and suxamethonium for use during rapid 
sequence induction of anaesthesia. Anaesthesia 1998; 53: 867-71.

8. Rasmussen LS, Viby-Mogensen J. Rapid sequence intubation- how? Acta AnaesthesiolScand 2007; 51: 787-8.

9. Magorian T, Flannery KB, Miller RD. Comparison of rocuronium, succinylcholine and vecuronium for rapidsequence induction of anesthesia in adult patients. Anesthesiology 1993Nov; 79(5): 913-16.

10. Mort TC. The incidence and risk factors for cardiac arrest during emergency tracheal intubation: A justification for incorporating the ASA Guidelines in the remote location. J Clin Anesth 2004; 16:508-16.

11. Davis DP, Hwang JQ, Dunford JV. Rate of decline in oxygen saturation at various pulse oximetry values with prehospital rapid sequence intubation. PrehospEmerg Care 2008; 12: 46-51.

12. Tang, L, Li S, Huang, S, Ma H, Wang Z. Desaturation following rapid sequence induction using succinylcholine vs. rocuronium in overweight patients. Acta AnaesthesiolScand 2011 Feb; 55: 203-8.

13. Vender JS, Szokol JW. Oxygen delivery systems, inhalation therapy, and respiratory therapy. In: Hagberg CA, ed. Benumof's Airway Management: Principles and Practice. 2nd ed. Philadelphia, PA: Mosby; 2007:321-345.

14. Hamilton WK, Eastwood DW. A study of denitrogenation with some inhalation anesthetic systems. Anesthesiology. 1955;16: 861-867.

15. Baraka AS, Taha SK, Aouad MT, et al. Preoxygenation: comparison of maximal breathing and tidal volume breathing techniques. Anesthesiology. 1999;91:612616.

16. Andrews JI, Kumar N, Van Den Brom RHG, Olkkola KT, Roest GJ, Wright PMC. A large simple randomized trial of rocuronium versus succinylcholine in rapid-sequence induction of anaesthesia along with propofol. Acta Anaesthesiol Scand. 1999; 43: 4-8.

17. El-Orbany MI, Joseph NJ, Salem MR. Tracheal intubating conditions and apnoea time after small-dose succinylcholine are not modified by the choice of induction agent. Br J Anaesth2005;95:710-14.

18. Nimmagadda U, Chiravuri SD, Salem MR, Joseph NJ, Wafai Y, Crystal GJ, ElOrbany MI. Preoxygenation with tidal volume and deep breathing techniques: the impact of duration of breathing and fresh gas flow. AnesthAnalg 2001; 92: 1337-41.

19. Gander S, Frascarolo P, Suter M, Spahn DR, Magnusson L. Positive end-expiratory pressure during induction of general anesthesia increases duration of nonhypoxic apnea in morbidly obese patients. AnesthAnalg 2005; 100: 580-4.

20. Herriger A, Frascarolo P, Spahn DR, Magnusson L. The effect of positive airway pressure during pre-oxygenation and induction of anaesthesia upon duration of non-hypoxic apnoea. Anaesthesia 2004; 59: 243-7.

21. Taha SK, Siddik-Sayyid SM, El-Khatib MF, Dagher CM, Hakki MA, Baraka AS. Nasopharyngeal oxygen insufflation following pre-oxygenation using the four deep breath technique. Anaesthesia 2006; 61: 427-30.

22. Baraka AS, Taha SK, Siddik-Sayyid SM, Kanazi GE, EL-Khatib MF, Dagher CM, Chehade JM, Abdallah FW, Hajj RE. Supplementation of pre-oxygenation in morbidly obese patients using nasopharyngeal oxygen insufflation. Anaesthesia 2007; 62: 769-73.

23. Baraka AS, Hanna MT, Jabbour SI, Nawfal MF, Sibai AA, Yazbeck VG, Khoury NI, Karam KS. Preoxygenation of pregnant and nonpregnant women in the 
head-up versus supine position. Anesth Analg. 1992 Nov; 75: 757-9.

24. Lane S, Saunder D, Schofield A, Padmanabhan R, Hildreth A, Laws D. A prospective, randomised controlled trial comparing the efficacy of preoxygenation in the 20 degrees head-up vs supine position. Anaesthesia 2005; 60:1064-7.

25. Dixon BJ, Dixon JB, Carden JR, Burn AJ, Schachter LM, Playfair JM, Laurie CP, O'Brien PE. Preoxygenation is more effective in the 25 degrees head-up position than in the supine position in severely obese patients: a randomized controlled study. Anesthesiology 2005; 102: 1110-5.

26. Altermatt FR, Munoz HR, Delfino AE, Cortinez LI. Pre-oxygenation in the obese patient: effects of position on tolerance to apnoea. Br J Anaesth 2005; 95: 706-709.

27. Fukuda, S, Wakuta, K, Ishikawa, T, Oshita, S, Sakabe, T, and Takeshita, H. Lidocaine modifies the effect of succinylcholine on muscle oxygen consumption in dogs. AnesthAnalg 1987; 66: 325-8.

28. Perry JJ, Lee J, Wells G. Are intubation conditions using rocuronium equivalent to those using succinylcholine? AcadEmerg Med 2002; 9: 813-23.

29. Sluga M, Ummenhofer W, Studer W, Siegemund M, Marsch SC. Rocuronium versus succinylcholine for rapid sequence induction of anesthesia and endotracheal intubation: A prospective, randomized trial in emergent cases. AnesthAnalg 2005; 101: 1356-61.

30. Lumb AB. Nunn's Applied respiratory physiology. $7^{\text {th }}$ edition. Oxford: Churchill Livingstone; 2010: 568.
31. Taha SK, El-Khatib MF, Baraka AS, Haidar YA, Abdallah FW, Zbeidy RA, Siddik-Sayyid SM: Effect of suxamethonium $v s$ rocuronium on onset of oxygen desaturation during apnoea following rapid sequence induction. Anaesthesia 2010; 65: 358-61.

32. Ha Harris CE, Murray AM, Anderson JM, Grounds RM, Morgan M. Effects of thiopentone, etomidate and propofol on the haemodynamic response to tracheal intubation. Anaesthesia 1988; 43: 32-6.

33. Sivilotti, M., Ducharme, J. Randomized, double-blind study on sedatives and hemodynamics during rapid-sequence intubation in the emergency department: The SHRED Study. Ann Emerg Med 1998; 31(3): 313-24.

34. Dobson AP, McCluskey A, Meakin G, Baker RD. Effective time to satisfactory intubating conditions after rocuronium in adults. Comparison of propofol and thiopentone for rapid sequence induction of anaesthesia. Anaesthesia 1999; 54: 1726.

35. Barr AM, Thornley BA: Thiopentone and suxamethonium crash induction. An assessment of the potential hazards. Anaesthesia 1976; 31: 23-9. 